\title{
PIBID: ANÁLISE DE PRODUÇÕES PUBLICADAS EM PERIÓDICOS DA ÁREA DA EDUCAÇÃO
}

\section{PIBID: ANALYSIS OF PRODUCTION PUBLISHED IN PERIODICS OF EDUCATION AREA}

\author{
PRODÓCIMO, Elaine \\ elaine@fef.unicamp.br \\ UNICAMP - Universidade Estadual de Campinas \\ PRADO, Guilherme do Val Toledo \\ gvptoledo@gmail.com \\ UNICAMP - Universidade Estadual de Campinas \\ AYOUB, Eliana \\ ayoubeliana@gmail.com \\ UNICAMP - Universidade Estadual de Campinas
}

\begin{abstract}
Resumo Este trabalho tem como objetivo analisar os artigos sobre o Pibid disponíveis na base de dados Scielo e no Portal de Periódicos da Capes. Para tal, fizemos uma revisão bibliográfica tomando como referência o descritor "Pibid", na qual foram selecionados um total de 26 artigos. As análises foram feitas a partir dos resumos dos textos e realizadas levando-se em conta: data da publicação, número de autores, instituição a que são vinculados, tipo de pesquisa, áreas de conhecimento e temáticas abordadas nos mesmos. Sendo o Pibid uma iniciativa que articula a relação universidade-escola e é constituído pelos sujeitos diretamente envolvidos na profissão docente é muito provável que o fomento promovido pelo programa esteja ampliando horizontes de possibilidades que devolvam aos professores e profissionais da educação o valor de sua própria constituição profissional, como mostram os artigos estudados e seus resultados.
\end{abstract}

Palavras-chave: Artigos científicos. Formação de professores. Parceria universidade-escola. Pibid.

\begin{abstract}
This work aims to analyze the articles about Pibid published in Scielo database and website Portal of Periodicals of Capes. To this end, we made a literature review with reference to the descriptor "Pibid" in which we reselected a total of 26 articles. Analyses were made from the abstracts of articles and performed taking into account: date of publication, number of authors, institution to which they are linked, type of research, areas of expertise and the issues addressed in them. Being the Pibid a program that articulates the university-school relationship and is formed by the people directly involved in the teaching profession is very likely that the program promoted new horizons of possibilities that return to teachers and education professionals the value of its own constitution professional, as shown in the analyzed studies and their results.
\end{abstract}


Key-words: Scientific articles. Teacher training. University-school partnership. Pibid. 1 INTRODUÇÃO

Em um quadro de preocupações internacionais e nacionais, a formação docente é uma constante nas agendas de diversos órgãos e agências, tais como a Organização Internacional do Trabalho (OIT), a Organização para a Cooperação e Desenvolvimento Econômico (OCDE) e a Organização das Nações Unidas para a Educação, Ciência e Cultura (Unesco). Observa-se, nas últimas décadas, um aumento no número de pesquisas sobre a formação, a carreira e a profissão docente em diversos países (China, Austrália, França, Finlândia, Portugal, Argentina, Brasil e Canadá, por exemplo). Isso revela a preocupação comum com a desvalorização da carreira do magistério e o crescente desinteresse dos jovens pela profissão docente.

Essas pesquisas, também realizadas no Brasil, analisam o trabalho docente $\mathrm{e}$ suas relações com a contemporaneidade, investigando os diversos motivos para a atratividade, ou não, da carreira de professor, as diversas diretrizes que a constituem no âmbito federal, estadual e municipal bem como os novos desafios tanto para esses profissionais no cotidiano do trabalho e as políticas públicas educacionais que nele incidem.

No contexto brasileiro, desde 2007, compete à Coordenação de Aperfeiçoamento de Pessoal de Nível Superior (CAPES) do Ministério da Educação (MEC), a partir da Lei n 11.502 de 11 de julho de 2007, a responsabilidade sobre a formação de professores para a educação básica e a valorização do magistério em todos os níveis e modalidades da educação.

O Programa Institucional de Bolsa de Iniciação à Docência (Pibid) foi criado em 2007 e, conforme consulta no site da Capes (BRASIL, 2008) ${ }^{1}$, "é uma iniciativa para o aperfeiçoamento e a valorização da formação de professores para a educação básica", sendo que os projetos de trabalho do programa visam à "inserção dos estudantes no contexto das escolas públicas desde o início da sua formação acadêmica para que desenvolvam atividades didático-pedagógicas" sob orientação de um professor da universidade e supervisão de um profissional da escola.

\footnotetext{
${ }^{1}$ Disponível em: <http://www.capes.gov.br/educacao-basica/capespibid>. Acesso em: 11 fev. 2015.
} 
O programa "concede bolsas a alunos de licenciatura participantes de projetos de iniciação à docência desenvolvidos por Instituições de Educação Superior (IES) em parceria com escolas de educação básica da rede pública de ensino". Da mesma forma, concede bolsas ao coordenador institucional, aos coordenadores de área de gestão de processos educacionais e aos coordenadores de área, responsáveis pela orientação dos bolsistas de iniciação à docência (bolsista ID) na universidade e aos supervisores, professores e profissionais das escolas públicas das redes de ensino municipal, estadual e federal. No ano de 2014, foram concedidas 90.254 bolsas aos participantes do programa, em 313 projetos de 284 $\mathrm{IES}^{2}$.

Por tratar-se de iniciativa recente, os estudos sobre o Pibid tornam-se relevantes como forma de acompanhamento do programa e para apontar possibilidades futuras no desenvolvimento de novos projetos ligados à formação de professores.

Nesse contexto, destacamos o artigo de Gatti et al. (2014), publicado pela Fundação Carlos Chagas, no qual os autores fazem uma ampla avaliação do Pibid e apontam para o alcance dessa política pública direcionada à formação docente.

Muito se tem produzido sobre o Pibid, com apresentação de trabalhos em eventos, tais como o Encontro Nacional de Didática e Prática de Ensino (Endipe), o Encontro Nacional das Licenciaturas (Enalic) e o Seminário Nacional do Pibid, além de publicações em forma de livros, artigos, dissertações, teses e trabalhos de conclusão de curso.

Nosso trabalho, juntando-se a outros que problematizam as produções relacionadas ao programa, tem como objetivo analisar os artigos sobre o Pibid disponíveis na base de dados Scielo (www.scielo.br) e no Portal de Periódicos da Capes (www.periodicos.capes.gov.br).

Para tal, fizemos uma revisão bibliográfica, cuja busca foi realizada no mês de agosto de 2014 tomando como referência o descritor "Pibid". Como critérios foram considerados somente artigos publicados em língua portuguesa. Foram obtidos

\footnotetext{
${ }^{2}$ Disponível em: <http://www.capes.gov.br/educacao-basica/capespibid/relatorios-e-dados>. Acesso em: 11 fev. 2015.
} 
quatro artigos no site Scielo e 31 artigos no Portal de Periódicos da Capes, desses sete em inglês e dois estavam repetidos, restando 22 artigos analisados.

As análises foram feitas a partir dos resumos dos textos, levando-se em conta: data da publicação, número de autores, instituição a que são vinculados, tipo de pesquisa (campo ou bibliográfica) (PRODÓCIMO; AYOUB, 2014), áreas de conhecimento e temáticas abordadas nos mesmos.

Embora em estudo realizado por Abramczuk et al. (2012), com objetivo de analisar a eficácia dos resumos acadêmicos em anunciar os aspectos centrais dos textos a eles referentes, tenha sido constatado que há problemas nos resumos no que diz respeito à apresentação de informações importantes, outros estudos têm utilizado esse tipo de investigação documental, como é o caso de La Taille, Souza e Vizioli (2004) e Vieira e Maciel (2007) que utilizaram esta metodologia de pesquisa para realizar uma análise sobre os periódicos da Capes. Porém, alertam sobre a dificuldade às vezes apresentada de se trabalhar com esse material, pois perceberam que os resumos variam em tamanho e na qualidade das informações apresentadas. Apesar desses limites apontados por diferentes autores, consideramos que a análise que trazemos a partir dos resumos dos 26 artigos pode colaborar para uma discussão acerca das produções relacionadas ao Pibid, bem como indicar possíveis lacunas reflexivas com o intuito de fomentar a pesquisa sobre um tema tão relevante na conjuntura educacional brasileira contemporânea.

\section{PANORAMA GERAL DOS ARTIGOS}

Foram levantados quatro artigos no Scielo e 22 no Portal de Periódicos da Capes e denominados para identificação: 1 a 4 seguido de $S$ para os artigos do Scielo e 1 a 22 seguido de $C$ para os do Portal de Periódicos da Capes (ex: 1S, 2S... e 1C, 2C). No quadro 1, apresentamos informações sobre os artigos selecionados.

Quadro 1: Artigos selecionados e analisados no estudo.

\begin{tabular}{|c|c|c|c|}
\hline & AUTORES & TÍTULO & REVISTA \\
\hline $1 S$ & Elaine Mateus & $\begin{array}{l}\text { Práticas de formação } \\
\text { colaborativa } \\
\text { professores/as de inglês: } \\
\text { representações de uma } \\
\text { experiência no Pibid }\end{array}$ & $\begin{array}{l}\text { RBLA, v.13, n.4, 2013, } \\
\text { p.1107-1130 }\end{array}$ \\
\hline
\end{tabular}




\begin{tabular}{|c|c|c|c|}
\hline $2 S$ & $\begin{array}{l}\text { Mayra Prates Albuquerque, } \\
\text { Lourdes Maria Bragagnolo } \\
\text { Frison, } \\
\text { Gliceane Caetano Porto }\end{array}$ & $\begin{array}{lr}\text { Memorial de formação } \\
\text { escrito no decorrer da } \\
\text { prática } & \text { docente: } \\
\text { aprendizagens } & \text { sobre } \\
\text { alfabetização } & \text { e } \\
\text { letramento } & \\
\end{array}$ & $\begin{array}{l}\text { Revista de Estudos } \\
\text { Pedagógicos, v.95, n.239, } \\
\text { 2014, p.73-86 }\end{array}$ \\
\hline $3 S$ & $\begin{array}{l}\text { Adair Aguiar Neitzel, } \\
\text { Cleide Jussar Muller Pareja, } \\
\text { Serenita Hochmann }\end{array}$ & $\begin{array}{l}\text { Práticas de leitura no } \\
\text { ensino médio: o Pibid de } \\
\text { Letras }\end{array}$ & 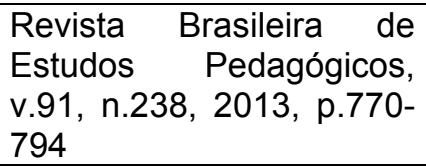 \\
\hline $4 S$ & $\begin{array}{l}\text { Maria Aparecida Bergamaschi, } \\
\text { Dóris Bittencourt Almeida }\end{array}$ & $\begin{array}{l}\text { Memórias escolares e } \\
\text { processos de iniciação à } \\
\text { docência }\end{array}$ & $\begin{array}{l}\text { Educação em Revista, } \\
\text { v.29, n.2, 2013, p.15-41 }\end{array}$ \\
\hline $1 \mathrm{C}$ & $\begin{array}{lll}\text { Maria José da Silva } \\
\text { Fernandes, } \\
\text { Sueli Guadelupe de Lima } \\
\text { Mendonça }\end{array}$ & $\begin{array}{l}\text { Pibid: uma contribuição à } \\
\text { política de formação } \\
\text { docente }\end{array}$ & $\begin{array}{l}\text { EntreVer, v.3, n.4, 2013, } \\
\text { p.220-236 }\end{array}$ \\
\hline $2 \mathrm{C}$ & 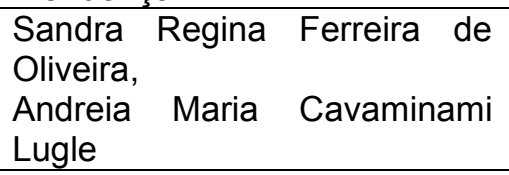 & $\begin{array}{l}\text { O Pibid/Pedagogia da } \\
\text { UEL: compondo a ação } \\
\text { docente }\end{array}$ & $\begin{array}{l}\text { EntreVer, v.3, n.4, 2013, } \\
\text { p.278-291 }\end{array}$ \\
\hline $3 \mathrm{C}$ & $\begin{array}{l}\text { José Rubens Lima Jardilino, } \\
\text { Andressa } \quad \text { Maris Rezende } \\
\text { Oliveri }\end{array}$ & $\begin{array}{l}\text { A formação continuada de } \\
\text { professores no âmbito do } \\
\text { Pibid na região de } \\
\text { Inconfidentes (MG) }\end{array}$ & $\begin{array}{l}\text { EntreVer, v.3, n.4, 2013, } \\
\text { p.237-249 }\end{array}$ \\
\hline $4 \mathrm{C}$ & $\begin{array}{l}\text { Jordana de Castro Balduíno, } \\
\text { Luelí Nogueira Duarte e Silva }\end{array}$ & $\begin{array}{l}\text { A relação teoria e prática } \\
\text { na formação de } \\
\text { professores: em foco o } \\
\text { Pibid Psicologia }\end{array}$ & $\begin{array}{l}\text { EntreVer, v.3, n.4, 2013, } \\
\text { p.250-261 }\end{array}$ \\
\hline $5 \mathrm{C}$ & $\begin{array}{l}\text { Angelo Priori, } \\
\text { Leandro Brunelo, } \\
\text { Letícia Aparecida Paixão }\end{array}$ & $\begin{array}{l}\text { História, ensino e } \\
\text { aprendizagem: a } \\
\text { experiência do Pibid de } \\
\text { História da Universidade } \\
\text { Estadual de Maringá }\end{array}$ & $\begin{array}{lr}\text { Diálogos, } & \text { v.16, } \\
\text { suplemento } & \text { especial, } \\
2012, \text { p.319-329 } & \end{array}$ \\
\hline $6 \mathrm{C}$ & Maria do Carmo Souza & $\begin{array}{l}\text { Formação docente nas } \\
\text { licenciaturas da UFSCar: } \\
\text { contribuições do Pibid }\end{array}$ & $\begin{array}{l}\text { Espaço Plural, ano XIII, } \\
\text { n.26, 2012, p.55-69 }\end{array}$ \\
\hline $7 \mathrm{C}$ & $\begin{array}{l}\text { Kellys Regina RodioSaucedo, } \\
\text { Kely Cristina Enis Weler, } \\
\text { Cléria Maria Wendling }\end{array}$ & $\begin{array}{l}\text { O diário de bordo na } \\
\text { formação de professores: } \\
\text { experiência no Pibid } \\
\text { Pedagogia }\end{array}$ & $\begin{array}{l}\text { Espaço Plural, ano XIII, } \\
\text { n.26, 2012, p.88-99 }\end{array}$ \\
\hline $8 \mathrm{C}$ & $\begin{array}{l}\text { Tais Aparecida de Moura, } \\
\text { Heloisa Chalmers Sisla } \\
\text { Cinquetti }\end{array}$ & $\begin{array}{l}\text { Aprendizagens } r \text { para } \\
\text { alfabetizar e letrar no } \\
\text { Pibid }\end{array}$ & $\begin{array}{l}\text { EntreVer, v.3, n.4, 2013, } \\
\text { p.292-306 }\end{array}$ \\
\hline $9 \mathrm{C}$ & $\begin{array}{l}\text { Ozaina Alves Targino, } \\
\text { Luan Duarte Souza, } \\
\text { Antonio Gautier Farias } \\
\text { Falconieri }\end{array}$ & $\begin{array}{llr}\text { Pibid/UERN } & \text { - uma visão } \\
\text { avaliativa } & \text { da } & \text { gestão } \\
\text { escolar } & \text { e } & \text { atuação } \\
\text { docente } & \text { em } & \text { uma } \\
\text { instituição } & \text { pública } & \text { de } \\
\text { ensino } & & \\
\end{array}$ & $\begin{array}{l}\text { Tchê Química, v.10, n.19, } \\
\text { 2011, p.46-56 }\end{array}$ \\
\hline $10 \mathrm{C}$ & $\begin{array}{l}\text { Costa, V.A.S.F., } \\
\text { Guedes, M.G.M., } \\
\text { de Oliveira, A.M.A., } \\
\text { de Souza, K.M.O., } \\
\text { Brito, A.M.S.S. }\end{array}$ & $\begin{array}{lr}\text { O processo } & \text { de } \\
\text { democratização } & \text { do } \\
\text { acesso ao ensino superior } \\
\text { e a importância do Pibid } \\
\text { no contexto dos alunos do }\end{array}$ & $\begin{array}{l}\text { Revista } \quad \text { Virtual } \\
\text { Química, v.5, n.2, 2013, } \\
\text { p.137-148 }\end{array}$ \\
\hline
\end{tabular}

\footnotetext{
${ }^{3}$ Não consta no artigo o nome completo dos autores.
} 


\begin{tabular}{|c|c|c|c|}
\hline & & $\begin{array}{l}\text { curso de licenciatura em } \\
\text { Química da UFRPE em } \\
\text { Serra Talhada } \\
\text { Pernambuco }\end{array}$ & \\
\hline $11 \mathrm{C}$ & $\begin{array}{l}\text { Marlete Sandra Diedrich, } \\
\text { Flávia Eloisa Caimi, } \\
\text { Adriana Bragagnolo }\end{array}$ & $\begin{array}{l}\text { A experiência de iniciação } \\
\text { à docência no contexto } \\
\text { das relações } \\
\text { universidade-escola: a } \\
\text { construção de uma } \\
\text { história marcada pelo ato } \\
\text { de dizer }\end{array}$ & $\begin{array}{l}\text { EntreVer, v.3, n.4, 2013, } \\
\text { p.262-277 }\end{array}$ \\
\hline $12 \mathrm{C}$ & $\begin{array}{l}\text { Nilson Marcos Dias Garcia, } \\
\text { Ivanilda Higa }\end{array}$ & $\begin{array}{l}\text { Formação de professores } \\
\begin{array}{lr}\text { de } & \text { Física: } \\
\text { problematizando } & \text { ações } \\
\text { governamentais } & \end{array}\end{array}$ & $\begin{array}{ll}\text { Educação: } & \text { Teoria e } \\
\text { Prática, v.22, n.40, 2012, } \\
\text { p. 166-183 }\end{array}$ \\
\hline $13 \mathrm{C}$ & $\begin{array}{l}\text { Jucirema Quinteiro, } \\
\text { Maria Eliza Chierighini } \\
\text { Pimentel. } \\
\text { Gisele Gonçalves }\end{array}$ & $\begin{array}{l}\text { A escola como espaço da } \\
\text { formação docente } \\
\text { universitária em debate }\end{array}$ & $\begin{array}{l}\text { EntreVer, v.3, n.4, 2013, } \\
\text { p.193-219 }\end{array}$ \\
\hline $14 \mathrm{C}$ & $\begin{array}{l}\text { Camile Martinelli Silveira, } \\
\text { Leonote Luzia Schmidt }\end{array}$ & $\begin{array}{l}\text { A percepção de uma } \\
\text { adolescente } \\
\text { multirrepetente sobre sua } \\
\text { trajetória escolar }\end{array}$ & $\begin{array}{l}\text { Poiésis, v.5, n.9, 2012, } \\
\text { p.300-317 }\end{array}$ \\
\hline $15 \mathrm{C}$ & $\begin{array}{l}\text { Gionara Tauchen, } \\
\text { Altair Fávero }\end{array}$ & $\begin{array}{l}\text { O princípio da } \\
\text { indissociabilidade } \\
\text { universitária: dificuldades } \\
\text { e possibilidades de } \\
\text { articulação }\end{array}$ & $\begin{array}{l}\text { Linhas críticas, v.17, n.33, } \\
\text { 2011, p.403-419 }\end{array}$ \\
\hline $16 \mathrm{C}$ & $\begin{array}{l}\text { Andréa Rosana Fetzner, } \\
\text { Maria Elena Viana Souza }\end{array}$ & $\begin{array}{lr}\text { Concepções } & \text { de } \\
\text { conhecimento escolar: } \\
\text { potencialidades } \\
\text { Programa Institucional de } \\
\text { Bolsa de Iniciação à } \\
\text { Docência }\end{array}$ & 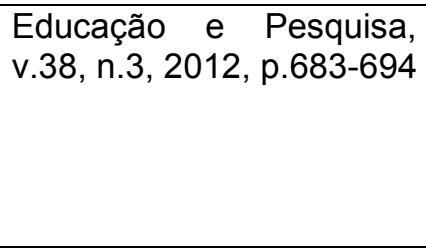 \\
\hline $17 \mathrm{C}$ & $\begin{array}{l}\text { Danielle Felisberto de Souza, } \\
\text { Manoel Nelito M. Nascimento }\end{array}$ & $\begin{array}{l}\text { Reflexões sobre as } \\
\text { relações étnico-raciais e a } \\
\text { identidade racial de } \\
\text { crianças do ensino } \\
\text { fundamental }\end{array}$ & $\begin{array}{l}\text { EntreVer, v.3, n.4, 2013, } \\
\text { p.307-321 }\end{array}$ \\
\hline $18 \mathrm{C}$ & Sydione Santos & $\begin{array}{l}\text { Formação inicial e prática } \\
\text { docente: percepções de } \\
\text { futuras professoras }\end{array}$ & $\begin{array}{l}\text { Olhar de Professor, v.15, } \\
\text { n.2, 2012, p.355-369 }\end{array}$ \\
\hline $19 \mathrm{C}$ & $\begin{array}{l}\text { Luis Ricardo Silva Queiroz, } \\
\text { Maura Penna }\end{array}$ & $\begin{array}{l}\text { Políticas públicas para a } \\
\text { Educação Básica e suas } \\
\text { implicações para o ensino } \\
\text { de música }\end{array}$ & $\begin{array}{l}\text { Educação, v.37, n.1, } \\
\text { 2012, p.91-106 }\end{array}$ \\
\hline $20 \mathrm{C}$ & Marli André & $\begin{array}{l}\text { Políticas e programas de } \\
\text { apoio aos professores } \\
\text { iniciantes no Brasil }\end{array}$ & $\begin{array}{l}\text { Cadernos de Pesquisa, } \\
\text { v.42, n.345, 2012, p.112- } \\
129\end{array}$ \\
\hline $21 \mathrm{C}$ & $\begin{array}{l}\text { Thamar Kalil-Alves, } \\
\text { Wellington de Oliveira }\end{array}$ & $\begin{array}{l}\text { O ensino de História da } \\
\text { América Latina no Brasil: } \\
\text { sobre currículos e } \\
\text { programas }\end{array}$ & $\begin{array}{lr}\text { Magis, } & \text { Revista } \\
\text { Internacional } & \text { de } \\
\text { Investigación } & \text { en } \\
\text { educación, v.3, n.6, 2011, } \\
\text { p.283-298 }\end{array}$ \\
\hline $22 \mathrm{C}$ & $\begin{array}{l}\text { Tânia Maria Rechia Schoeder, } \\
\text { Cléria Maria Wendling }\end{array}$ & $\begin{array}{l}\text { Contribuições do Pibid } \\
\text { para a formação do } \\
\text { pedagogo }\end{array}$ & $\begin{array}{l}\text { Contribuciones a las } \\
\text { Ciencias Sociales, } 25, \\
\text { 2013, p.1-9 }\end{array}$ \\
\hline
\end{tabular}


Fonte: Autoria própria.

Em relação à data de publicação dos artigos, os dados encontram-se na tabela 1.

Tabela 1: Data de publicação dos artigos.

\begin{tabular}{l|llllll}
\hline & 2010 & 2011 & 2012 & 2013 & 2014 & total \\
\hline Scielo & 0 & 0 & 0 & 3 & 1 & 4 \\
Capes & 1 & 1 & 9 & 11 & 0 & 22 \\
& 1 & 1 & 9 & 14 & 1 & 26 \\
\hline
\end{tabular}

Fonte: Autoria própria.

Conforme dissemos anteriormente, o Pibid foi criado em 2007, e o primeiro artigo foi publicado nas bases analisadas em 2010. Pensamos que esse período de tempo foi necessário para que as experiências com o programa se tornassem efetivas e possíveis de serem analisadas e registradas. Cabe destacar que no ano de 2013, foi lançado um número da revista "EntreVer" todo dedicado à formação de professores e ao Pibid, o que pode justificar o maior número de publicações no ano, sendo oito no total apenas nessa revista.

Embora o levantamento dos dados tenha ocorrido no mês de agosto de 2014, apenas uma publicação foi registrada até então nesse ano. É possível que as publicações tenham sido direcionadas a outros periódicos, não registrados nos sites analisados, ou mesmo que a realização de eventos envolvendo diretamente a temática da educação (Endipe, Enalic e Seminário Nacional do Pibid), tenha ocasionado uma diminuição nas publicações em periódicos e um possível aumento nas publicações em anais de congressos.

Os dados referentes ao número de autores encontram-se na Tabela 2.

Tabela 2: Número de autores por artigo.

\begin{tabular}{l|llllll}
\hline & 2010 & 2011 & 2012 & 2013 & 2014 & Total \\
\hline 1 autor & & & 2 artigos & 2 artigos & & 4 \\
2 autores & 1 artigo & 1 artigo & 4 artigos & 8 artigos & & 14 \\
3 autores & & & 3 artigos & 3 artigos & 1 artigo & 7 \\
+3 autores & & & & 1 artigo & & 1 \\
\hline
\end{tabular}

Fonte: Autoria própria. 
Houve predominância de artigos escritos por dois autores. No total, somaramse 58 autores e quanto à vinculação ao Pibid, apenas constam informações nos artigos sobre 21 autores sendo: três coordenadores institucionais, dois coordenadores de área de gestão de processos educacionais, dez coordenadores de área, quatro bolsistas ID e dois ex-bolsistas ID. Embora outros dois autores identifiquem-se como professores da rede básica, não há em nenhum dos artigos identificação como supervisor do Pibid. Chama a atenção a não (ou pouca) participação dos professores supervisores nos artigos publicados, o que pode demonstrar uma visão corrente de que a dimensão da pesquisa seja de responsabilidade da universidade.

Quanto aos periódicos, os 26 artigos foram publicados em 16 revistas distintas, sendo oito deles na revista EntreVer, $(\mathrm{A} 1 \text { - História })^{4}$, dois nas revistas Espaço Plural (B2 - Planejamento Urbano e Regional/ Demografia) e Revista Brasileira de Estudos Pedagógicos (A2 - Interdisciplinar) e um artigo nas revistas: Educação em Revista (A1 - Interdisciplinar), Revista Brasileira de Linguística Aplicada (A1 - Letras/Linguística), Diálogos (A2 - Interdisciplinar, História), Tchê Química (B3 - Ensino), Revista Virtual de Química (B2 - Interdisciplinar, Materiais), Educação Teoria e Prática (B2 - Interdisciplinar, Educação, Geografia), Poiésis (B3 - Interdisciplinar, Educação, Filosofia, Ensino, Psicologia), Linhas Críticas (B1 Interdisciplinar, Educação), Educação e Pesquisa (A1 - Educação), Olhar de Professor (B1 - Administração, Ciências Contábeis e Turismo), Educação (B1 Interdisciplinar, Educação), Cadernos de Pesquisa (B4 - Geografia), Magis (B3 Educação), Contribuciones a las Ciencias Sociales (B2 - Interdisciplinar, Geografia, Direito, Educação, Letras/Linguística, Serviço Social). Todos os periódicos estão indexados no sistema Qualis de diferentes áreas.

A presença de um número especial da revista EntreVer dedicado ao programa demonstra a relevância do mesmo no contexto da formação de professores e na educação brasileira. Importante ressaltar a necessidade de outras revistas também dedicarem espaço ao Pibid.

No que se refere à vinculação dos autores, os dados encontram-se na Tabela 3.

\footnotetext{
${ }^{4}$ Foram inseridas as maiores indexações de cada revista no sistema Web Qualis.
} 
Tabela 3: Vinculação dos autores dos artigos.

\begin{tabular}{l|llllll}
\hline & 2010 & 2011 & 2012 & 2013 & 2014 & total \\
\hline Públicas & 1 & 0 & 7 & 13 & 1 & 22 \\
$\begin{array}{l}\text { Privadas } \\
\begin{array}{l}\text { Públicas e } \\
\text { privadas }\end{array}\end{array}$ & 0 & 0 & 2 & 1 & 0 & 3 \\
Total & 1 & 1 & 0 & 0 & 0 & 1 \\
\hline
\end{tabular}

Dos 26 artigos publicados, 22 deles os autores têm vinculação com universidades públicas. Esse fato pode dever-se à destinação dos primeiros editais do programa: o edital 2007, primeiro ano do Pibid, foi restrito às universidades federais; em 2009, ampliou-se para as universidades estaduais e municipais; em 2010, além daquelas, também as universidades filantrópicas e comunitárias foram contempladas, sendo aberto para todas as universidades, inclusive as privadas apenas no edital 2013. Além disso, as universidades públicas são aquelas com maior tradição na produção científica.

Quanto às áreas de conhecimento temos que, em oito dos 26 artigos, não é especificada uma área, mas abordam o Pibid como um todo ou as diferentes áreas que compõem o Pibid na IES; nove tratam de programas na área da Pedagogia, sendo a que contempla maior número de artigos; História, Letras e Química tiveram dois artigos sobre a temática, sendo que um dos artigos de Química trata também da Física, Biologia e Matemática; e, por fim, um artigo aborda as áreas de: Psicologia, Física e Música. O Pibid engloba atualmente as seguintes áreas, segundo informações obtidas no site do programa: Artes plásticas e visuais, Biologia, Ciências, Ciências Agrárias, Ciências Sociais, Dança, Educação do Campo, Educação do Campo - Ciências da natureza e Matemática, Educação do Campo - Ciências Humanas e Sociais, Educação do Campo - Linguagens e Códigos, Educação Especial, Educação Física, Enfermagem, Ensino religiosos, Filosofia, Física, Geografia, História, Informática, Intercultural indígena, Intercultural indígena - Ciências da natureza, Intercultural indígena Ciências Humanas e Sociais, Intercultural Indígena e Linguagens e Códigos, Interdisciplinar, Interdisciplinar Educação Do Campo, Interdisciplinar - Intercultural Indígena, Letras - Alemão, Letras - Espanhol, Letras - Francês, Letras - Inglês, Letras - Italiano, Letras Libras, Letras - Português, Matemática, Música, Pedagogia, Psicologia, Química e 
Teatro, totalizando 39 distintas áreas de formação de professores. No entanto, entre os artigos analisados, somente sete áreas de conhecimento foram contempladas.

Dos 26 trabalhos selecionados, temos 15 estudos de campo, sete relatos de experiência, duas análises de documentos e dois ensaios. É possível verificar a prevalência dos estudos de campo e relatos de experiência. Segundo André (2001), a partir da década de 1980 e 1990, os estudos na área da educação centraram seus olhares para "dentro" da escola, voltando-se para análises sobre situações concretas ocorridas no cotidiano.

Em relação às áreas abordadas nos artigos, identificamos que a Pedagogia foi a com maior número de trabalhos. Destacamos, ainda, algumas temáticas gerais tratadas nas produções aqui analisadas: contribuição e importância do Pibid na formação dos licenciandos; contribuição e importância do Pibid para os supervisores; interdisciplinaridade; relação teoria e prática; e relação universidadeescola. Esses são temas recorrentemente discutidos em diferentes publicações relativas ao Pibid Brasil afora, como podemos constatar inclusive na pesquisa feita por Gatti et al (2014, p.104-106), na qual apresentam uma série de contribuições do programa para os cursos de licenciatura, para os estudantes bolsistas, para os professores supervisores da escola, para os professores das IES, para as escolas e seus alunos, na relação IES e escola pública e como política pública de educação. Nos 3 volumes da coleção "Formação Docente em Diálogo", organizada pela coordenação institucional do Pibid/Unicamp, publicados em 2014 (PRADO; AYOUB, 2014b, 2014c, AYOUB; PRADO, 2014), encontramos, igualmente, diferentes artigos que refletem sobre os temas acima mencionados.

Dentre as temáticas tratadas, destacamos a "interdisciplinaridade" como uma que vem ganhando novos espaços reflexivos e construindo outras perspectivas no âmbito da formação docente. No geral, o trabalho interdisciplinar encontra muitos entraves no âmbito escolar, devido à tradição disciplinar que delimita tanto os currículos escolares quanto a própria formação docente.

Soma-se a isso a quase inexistência de um amparo institucional para o planejamento e implementação de ações efetivamente interdisciplinares, além da sobrecarga de trabalho, levando os professores a dedicarem-se quase que exclusivamente para as tarefas relativas aos seus próprios conteúdos, não havendo muitas possibilidades de trocas com professores 
de outras áreas para o desenvolvimento de ações conjuntas. (PRODÓCIMO; AYOUB, 2014, p.84).

Pelo que podemos inferir, a temática "interdisciplinaridade" presente nas ações de iniciação à docência mencionadas neste conjunto de artigos tem como objetivos primordiais, assim como identificamos nos subprojetos do Pibid/Unicamp:

[...] articular os saberes universitários das diferentes áreas de formação e realizar propostas educativas nas escolas marcadamente interdisciplinares, seja pelas ações coletivas em que participam os bolsistas ID de áreas distintas, seja pelas ações pedagógicas que exigem um tratamento interdisciplinar em sua concretização. (PRADO; AYOUB, 2014a, p.29).

Apresentamos a seguir, três quadros com as sínteses dos artigos, os quais estão distribuídos em: artigos da área de Pedagogia; artigos gerais; e demais artigos. Tal subdivisão foi organizada tendo em vista a possibilidade de agrupamento por grandes temas e permitir uma melhor visualização do conteúdo temático reflexivo de cada artigo.

Quadro 2: Síntese dos artigos específicos com produção na área de pedagogia.

\begin{tabular}{|l|l|}
\hline 2S & $\begin{array}{l}\text { Trata das experiências e aprendizados de uma aluna de Pedagogia. Por meio de } \\
\text { memorial reflexivo, foram analisadas as contribuições do Pibid para sua formação e } \\
\text { também para os alunos da escola. }\end{array}$ \\
\hline 4S & $\begin{array}{l}\text { Trata das experiências de 14 estudantes de Pedagogia, também por meio de narrativas } \\
\text { de memórias. Faz uma análise do Pibid no percurso formativo. }\end{array}$ \\
\hline 2C & $\begin{array}{l}\text { Apresenta ações do Pibid na universidade que envolvem a interdisciplinaridade e a } \\
\text { Pedagogia de projetos. Traz uma abordagem dos desafios da docência. }\end{array}$ \\
\hline 7C & $\begin{array}{l}\text { Apresenta atividades desenvolvidas no Pibid na universidade. Destaca o fortalecimento } \\
\text { da formação inicial do pedagogo em diferentes âmbitos, fruto da relação com a escola, } \\
\text { bem como na elaboração de materiais didáticos, artigos, propostas e planos de trabalho. }\end{array}$ \\
\hline 8C & $\begin{array}{l}\text { Traz as contribuições do Pibid em relação à aprendizagem da docência na alfabetização } \\
\text { e letramento. Destaca os desafios vivenciados pelas bolsistas na experiência docente. }\end{array}$ \\
\hline 13C & $\begin{array}{l}\text { Analisa a experiência com o Pibid na universidade. Busca responder duas questões: } \\
\text { possibilidades da escola pública brasileira de contribuir na formação de estudantes e o } \\
\text { impacto dessa política na formação universitária. }\end{array}$ \\
\hline 16C & $\begin{array}{l}\text { Discute concepções de conhecimento escolar e desafios de projetos desenvolvidos em } \\
\text { instituições com perspectivas interculturais. As concepções apresentadas oscilam entre } \\
\text { conservadoras e emancipatórias. }\end{array}$ \\
\hline 18C & $\begin{array}{l}\text { Analisa vivências de estudantes de Pedagogia em classes de alfabetização. Destaca a } \\
\text { importância da problematização das experiências. }\end{array}$ \\
\hline 22C & Discute as contribuições do Pibid na formação do pedagogo. \\
\hline
\end{tabular}

Esse conjunto de textos versa, principalmente, sobre as contribuições do Pibid na formação dos futuros professores, apresentam as propostas colocadas em 


\section{ação nas universidades e debatem os desafios da docência. A problematização} dessas temáticas é realizada tomando como material de análise, sobretudo as produções dos alunos bolsistas por meio de relatos, narrativas e memórias.

Quadro 3: Síntese dos artigos que tratam do Pibid de maneira geral.

\begin{tabular}{|l|l|}
\hline $1 \mathrm{C}$ & $\begin{array}{l}\text { Trata do impacto, a partir da experiência da universidade, do Pibid na formação de } \\
\text { professores, das contribuições para a relação universidade e escola e dos avanços na } \\
\text { política de formação inicial de professores. }\end{array}$ \\
\hline 3C & $\begin{array}{l}\text { Aborda a importância do programa para a formação continuada e rotina da escola a } \\
\text { partir da participação dos professores como supervisores no Pibid. Analisa as } \\
\text { dificuldades e os contextos formativos. }\end{array}$ \\
\hline 6C & $\begin{array}{l}\text { Reflete sobre as contribuições do Pibid à formação docente e ao professor supervisor } \\
\text { como formação continuada. Apresenta e analisa as ações realizadas pelo programa. }\end{array}$ \\
\hline $11 \mathrm{C}$ & $\begin{array}{l}\text { Discute as experiências dos bolsistas na relação entre teoria e prática, e universidade e } \\
\text { escola pública. }\end{array}$ \\
\hline 15C & $\begin{array}{l}\text { Analisa as relações entre ensino, pesquisa e extensão em uma universidade. Cita o } \\
\text { Pibid como um dos projetos possíveis de articulação disciplinar. }\end{array}$ \\
\hline 20C & $\begin{array}{l}\text { Analisa estudos de caso sobre políticas voltadas aos professores iniciantes e à inserção } \\
\text { na docência. }\end{array}$ \\
\hline
\end{tabular}

Fonte: Autoria própria.

Quadro 4: Síntese artigos que tratam de maneira específica de outras áreas do conhecimento.

\begin{tabular}{|c|c|c|}
\hline Letras & $1 \mathrm{~S}$ & $\begin{array}{l}\text { Analisa representações de práticas de formação colaborativas de } \\
\text { professores/as de Inglês. Aborda as implicações de posições híbridas } \\
\text { sobre a formação docente. }\end{array}$ \\
\hline Letras & $3 S$ & $\begin{array}{l}\text { Discute estratégias de leitura desenvolvidas por bolsistas ID e } \\
\text { concepções que embasam suas ações na formação de leitores no ensino } \\
\text { médio. }\end{array}$ \\
\hline Química & $9 \mathrm{C}$ & $\begin{array}{l}\text { Apresenta uma caracterização da gestão escolar e atuação docente nas } \\
\text { disciplinas de ciências naturais e matemática, possibilitando } \\
\text { conhecimento da rotina e problemas das escolas para direcionamento } \\
\text { das ações do Pibid. }\end{array}$ \\
\hline Química & $10 \mathrm{C}$ & $\begin{array}{l}\text { Traz uma investigação sobre o processo de democratização do acesso } \\
\text { ao ensino superior e a importância do Pibid na licenciatura de Química da } \\
\text { Universidade Federal Rural de Pernambuco (UFRPE). }\end{array}$ \\
\hline História & $5 \mathrm{C}$ & $\begin{array}{l}\text { Analisa a colaboração do programa para a formação dos licenciandos por } \\
\text { meio da experiência, que tem propiciado maior compreensão da } \\
\text { realidade educacional do país e do ensino da História. }\end{array}$ \\
\hline História & $21 \mathrm{C}$ & $\begin{array}{l}\text { Apresenta os percursos do ensino de história da América Latina no Brasil, } \\
\text { especificamente no ensino médio. }\end{array}$ \\
\hline Psicologia & $4 \mathrm{C}$ & Analisa a concepção de teoria e prática do Pibid. \\
\hline Música & $19 \mathrm{C}$ & $\begin{array}{l}\text { Analisa políticas públicas ligadas à educação básica que se referem ao } \\
\text { ensino de música, ressaltando que há necessidade de maior participação } \\
\text { da educação musical nas políticas educacionais. }\end{array}$ \\
\hline Física & 12C & $\begin{array}{l}\text { Discute ações e políticas públicas implementadas pelo Ministério da } \\
\text { Educação que afetam a formação de professores, principalmente na área } \\
\text { da Física. }\end{array}$ \\
\hline $\begin{array}{l}\text { Não } \\
\text { especifica }\end{array}$ & 14C & $\begin{array}{l}\text { Analisa a percepção de uma aluna multirrepetente sobre sua trajetória } \\
\text { escolar, por meio de um estudo de caso acompanhado pelo programa. }\end{array}$ \\
\hline $\begin{array}{l}\text { Não } \\
\text { especifica }\end{array}$ & $17 \mathrm{C}$ & $\begin{array}{l}\text { Apresenta e reflete sobre as atividades desenvolvidas com tema das } \\
\text { relações étnico-raciais com enfoque na formação da identidade. }\end{array}$ \\
\hline
\end{tabular}


Como podemos observar, as análises construídas em cada um destes artigos, indicam-nos que os processos de formação mobilizados pelo Pibid vão além da simples transformação pessoal dos sujeitos participantes. Vemos que as consequências para a constituição de um "ethos" profissional alicerçado no diálogo entre os diferentes participantes do programa e pelas compreensões dos processos educativos construídos por diferentes subprojetos de trabalho acenam para novas possibilidades formativas e para uma maior integração entre os diferentes atores da formação da profissão docente.

É possível verificar, pelos trabalhos analisados, pouca produção que envolva mais diretamente os profissionais que atuam como supervisores dos projetos. A maior parte dos estudos envolve os próprios bolsistas de iniciação à docência, as atividades desenvolvidas ou, ainda, a importância do programa para a formação do professor e para o vínculo universidade-escola, mas poucos tratam da contribuição do Pibid aos professores supervisores, inclusive como possibilidade de formação continuada a esses profissionais.

Muitas propostas têm sido adotadas em relação à formação continuada de professores. A justificativa, muitas vezes, refere-se à melhoria da qualidade da educação, como se a causa dos problemas da escola repousasse na má formação inicial do professor, que seria sanada com cursos de atualização que visam a aumentar a competência do professor (SOUZA, 2006). Contudo, as formas adotadas (cursos de curta ou longa duração, presenciais, semipresenciais ou a distância), segundo Souza (2006), não levam em conta as condições de trabalho concretas dos professores e as relações interpessoais que se dão no contexto escolar. Consideramos que a participação do professor como supervisor do Pibid possibilita, por meio da proximidade entre universidade e escola, das discussões sistemáticas, do contato com os alunos bolsistas, um processo contínuo de reflexão sobre a prática docente que se configura como um espaço efetivo de qualificação profissional, uma vez que possibilita levar em conta aspectos muitas vezes negligenciados em outros espaços de formação continuada relacionados ao contexto de trabalho nas escolas.

Outro ponto a ser destacado é que as produções aqui analisadas não envolvem a diversidade de áreas contempladas pelos projetos institucionais do Pibid 
desenvolvidos nas diferentes regiões do Brasil. Embora o programa tenha um amplo alcance, não foram encontrados nos periódicos analisados trabalhos que contemplem grande parte dos cursos de formação de professores envolvidos nessa ação institucional.

\section{CONSIDERAÇÕES FINAIS}

Como pôde ser visto nas sínteses acima apresentadas, a importância do Pibid para a formação dos estudantes bolsistas foi o tema mais abordado nos artigos.

O Pibid, ao instaurar uma dinâmica de ação em que os bolsistas têm a possibilidade de mergulhar no cotidiano da escola, na rotina dos docentes e dos alunos, fomenta a constituição de uma estreita relação entre a universidade e a escola.

\footnotetext{
Nesse contexto, o diálogo entre os saberes da formação e os saberes experienciais produzem novos questionamentos para a atual formação docente universitária, principalmente no que concerne à relação entre teoria e prática, tendo em vista um olhar para a formação em que a pesquisa não esteja apartada da docência [...] (PRADO; AYOUB, 2014a, p.32).
}

Esse contato sistemático com a escola, com os professores mais experientes, com os alunos, com a equipe de gestão escolar, com os funcionários, pode viabilizar aprendizados diversos que vão propiciar um conhecimento mais profundo da realidade escolar, seus limites e suas possibilidades. Nesse sentido, diferente do que já alertava Nóvoa em 1999, a respeito do excesso de discursos educacionais e da pobreza no âmbito das práticas pedagógicas, inclusive na formação de professores, o PIBID, mais de uma década depois, tem proporcionado um novo alento às diversas experiências formativas no contexto da formação docente. Podemos perceber, a partir dos artigos analisados, que o programa procura realizar uma integração das dimensões cotidianas da profissão docente nas diferentes graduações que formam professores, possibilitando que cada um dos estudantes incorporem à sua pessoalidade, aspectos essenciais do ethos profissional docente, antes mesmo de sua inserção no mundo do trabalho escolar.

Uma experiência de formação docente que é acompanhada simultaneamente pelo profissional da escola e pelo profissional da universidade, realizando uma 
supervisão reflexiva como abordada por Sá-Chaves (2000) e Alarcão (2003) e que não fica limitada somente aos aspectos relativos ao ensino de uma disciplina, mas caminha no sentido de numa perspectiva profissional mais ampla, tanto cultural como educacional.

Por outro lado, a importância do Pibid para a formação dos supervisores também se fez presente em alguns artigos analisados. Consideramos que diante de um quadro social em que a profissão docente é pouco valorizada e em que os professores sentem-se sozinhos para a solução de seus problemas, um programa que se propõe a valorizar a experiência docente, por meio da contribuição na formação de novos professores, bem como por meio de uma remuneração extra pelo seu trabalho, pode trazer repercussões relevantes para a formação inicial e continuada de professores.

Concordamos com Nóvoa (2009, p.211) quando afirma:

[...] insisto en la necesidad de devolver la formación de profesores a los profesores, porque el refuerzo de procesos de formación basados en la investigación solo tiene sentido si éstos se construyen dentro de la profesión. ${ }^{5}$

Sendo o PIBID uma iniciativa que articula a relação universidade-escola e é constituído pelos sujeitos diretamente envolvidos na profissão docente - professores da universidade, licenciandos futuro-professores e professores e profissionais de escolas do sistema público de ensino - é muito provável que o fomento promovido pelo programa esteja ampliando horizontes de possibilidades que devolvam aos professores e profissionais da educação o valor de sua própria constituição profissional, como mostram os artigos estudados e seus resultados.

É sabido que os textos aqui analisados não representam o todo dos trabalhos produzidos sobre o Pibid e que a característica dos veículos analisados, revistas indexadas, muitas vezes prima por um tipo de escrita que envolve um rigor acadêmico-científico que acaba por restringir a autoria aos profissionais do ensino superior que estão mais preparados para atuar no âmbito da pesquisa. A despeito disso, chama a atenção o fato de poucos supervisores figurarem entre os autores

\footnotetext{
5 “[...] insisto na necessidade de devolver a formação de professores aos professores, porque o reforço de processos de formação baseados na pesquisa só tem sentido se estas se construírem dentro da profissão". (tradução livre dos autores)
} 
dos textos analisados. É possível, contudo, que em outras publicações (livros, dissertações, teses etc.) ou em outros espaços de divulgação (sites, blogs etc.), sejam apresentados mais trabalhos envolvendo os professores e profissionais das redes de ensino, dentre os quais, aqueles que analisem a contribuição do programa para sua ação profissional.

Ademais a essas considerações, é importante salientar a relevância de estudos que investiguem e reflitam sobre o programa, trazendo reflexões para seu aprimoramento.

\section{ELAINE PRODÓCIMO}

Docente da Faculdade de Educação Física da Universidade Estadual de Campinas (Unicamp). Coordenadora de área de gestão de processos educacionais do PibidUnicamp.

\section{GUILHERME DO VAL TOLEDO PRADO}

Docente da Faculdade de Educação da Universidade Estadual de Campinas (Unicamp). Coordenador institucional do Pibid-Unicamp.

\section{ELIANA A YOUB}

Docente da Faculdade de Educação da Universidade Estadual de Campinas (Unicamp). Coordenadora de área de gestão de processos educacionais do PibidUnicamp.

\section{REFERÊNCIAS}

ABRAMCZUK, C. et al. Metodologia Científica: análise e reflexão sobre a eficácia dos resumos de artigos acadêmicos. Perspectivas em Gestão e Conhecimento, v. 2, n. 1, p. 170-181, jan./jun. 2012.

ALARCÃO, I. Professores reflexivos em uma escola reflexiva. São Paulo: Editora Cortez, 2003. 112 p.

ANDRÉ, M. E. D. A. Pesquisa em Educação: buscando rigor e qualidade. Cadernos de Pesquisa, v.113, p.51-64, julho/ 2001.

AYOUB, E.; PRADO, G. V. T. (Orgs). Pibid-Unicamp: construindo parcerias entre a universidade e a escola pública. Campinas: Leitura Crítica, 2014. (Coleção:

Formação docente em diálogo; v.2) Disponível em:

<http://www.pibid.unicamp.br/index.php/publicacoes>. Acesso em: 27 jan. 2015. 
BRASIL. Coordenação de Aperfeiçoamento de Pessoal de Nível Superior - Capes. Programa institucional de Bolsas de Iniciação à Docência - Pibid, 2008. Disponível em <http://www.capes.gov.br/educacao-basica/capespibid>. Acesso em: 11 fev. 2015 .

GATTI, B. A. et al. Um estudo avaliativo do Programa Institucional de Bolsa de Iniciação à Docência (Pibid). São Paulo: FCC/SEP, 2014. 117 p.

LA TAILLE, Y. de; SOUZA, L. S.; VIZIOLI, L. Ética e educação: uma revisão da literatura educacional de 1990 a 2003. Educação e Pesquisa, v.30, n.1, p.91-108, jan./apr. 2004

NÓVOA, A. Os Professores na Virada do Milênio: do excesso dos discursos à pobreza das práticas. Educação e Pesquisa, São Paulo, v.25, n.1, p.11-20, jan./jun. 1999.

Para una formación de profesores construida dentro de la profesión. Revista de Educación, 350, p.203-218, set/dez. 2009.

PRADO, G. V. T.; AYOUB, E. Pibid-Unicamp: criando uma nova cultura de valorização docente. In: PRADO, G. V. T.; AYOUB, E. (Orgs). Pibid-Unicamp: criando uma nova cultura nos cursos de formação de professores. Campinas: Leitura Crítica, 2014a.p.17-33. (Coleção: Formação docente em diálogo; v.1). Disponível em: <http://www.pibid.unicamp.br/index.php/publicacoes>. Acesso em: 22 jan. 2015.

. (Orgs). Pibid-Unicamp: criando uma nova cultura nos cursos de formação de professores. Campinas: Leitura Crítica, 2014b. (Coleção: Formação docente em diálogo; v.1). Disponível em: <http://www.pibid.unicamp.br/index.php/publicacoes>. Acesso em: 22 jan. 2015.

(Orgs). Pibid-Unicamp: ampliando horizontes na formação de professores. Campinas: Leitura Crítica, 2014c. (Coleção: Formação docente em diálogo; v.3). Disponível em: <http://www.pibid.unicamp.br/index.php/publicacoes>. Acesso em: 30 jan. 2015.

PRODÓCIMO, E.; AYOUB, E. Relações humanas e cotidiano escolar: experiências interdisciplinares no Pibid-Unicamp. In: AYOUB, E.; PRADO, G. V. T. (Orgs). PibidUnicamp: construindo parcerias entre a universidade e a escola pública. Campinas: Leitura Crítica, 2014. p.73-96 (Coleção: Formação docente em diálogo; v.2). Disponível em: <http://www.pibid.unicamp.br/index.php/publicacoes>. Acesso em: 27 jan. 2015.

SÁ-CHAVES, I. Formação, conhecimento e supervisão: contributos nas áreas da formação de professores e de outros profissionais. Aveiro: Universidade de Aveiro, 2000. (Estudos temáticos 1). 183 p.

SOUZA, D. T.R. Formação Continuada de professores e fracasso escolar: problematizando o problema da incompetência. Educação e Pesquisa, v.32, n.3, p. 77-492, set/dez 2006. 
Atos de Pesquisa em Educação - ISSN 1809-0354

Blumenau, v. 10, n.2, p.393-410, mai./ago. 2015

DOI: http://dx.doi.org/10.7867/1809-0354.2015v10n2p393-410 410

VIEIRA, R. A.; MACIEL, L. S. B. Fonte investigadora em Educação: registros do banco de teses da CAPES. Educação e Pesquisa, v.33, n.2, p.353-367, mai/ago. 2007. 